\title{
Museu Aberto do Descobrimento (MADE) na Bahia, Brasil: GEOSSISTEMA E VULNERABILIDADE AMBIENTAL
}

\author{
Renata Coppieters Oliveira de Carvalho ${ }^{1 *}$, Felipe de Souza Pimenta $^{2}$, Alexandre Schiavetti ${ }^{3}$
}

1 Departamento de Ciências Humanas e Tecnologia, Universidade Estadual da Babia - UNEB. Campus XVIII, Eunápolis Bahia. Programa de Pós Graduação em Desenvolvimento Regional e Meio Ambiente - Rede Prodema, Universidade Estadual de Santa Cruz - UESC

2 Programa de Pós Graduação em Desenvolvimento Regional e Meio Ambiente - Rede Prodema, Universidade Estadual de Santa Cruz - UESC

3 Laboratório de Etnoconservação e Áreas Protegidas, Departamento de Ciências Agrárias e Ambientais. Universidade Estadual de Santa Cruz, Ilbéus, Babia, Brasil. Investigador Associado CESIMAR, CENPAT. Chubut, Argentina. de Pos Graduação em Desenvolvimento Regional e Meio Ambiente Rede Prodema, Universidade Estadual de Santa Cruz-UESC

*Autorpara correspondência: renatacopi@hotmail.com

Recebido em 17 de julho de 2017. Aceito em 19 de dezembro de 2018. Publicado em 28 de dezembro de 2018.

Resumo - Este artigo tem como objetivo analisar o Geossistema do Museu Aberto do Descobrimento, de forma a medir sua vulnerabilidade ambiental. Especificamente, caracterizar o meio biótico, físico e socioeconômico; elaborar um mapa de vulnerabilidade ambiental relativa e sugerir mudanças de usos com base na Política Nacional sobre Mudanças do Clima. A área é tombada como patrimônio histórico pelo IPHAN desde1996 e ocupa os municípios de Santa Cruz Cabrália, Porto Seguro e Prado na Bahia. O turismo é a principal atividade do setor de serviços. Utilizou-se uma abordagem descritiva dos ambientes a partir de mapas e dados secundários, tendo como aporte teórico a Teoria dos Geossistemas. O mapa de vulnerabilidade foi elaborado a partir da sobreposição dos mapas temáticos no SIG Arcgis 10.1, as informações cartográficas foram rasterizadas e seus atributos reclassificados. Foram atribuídos graus de vulnerabilidade para cada componente dos fatores físicos ambientais, segundo suas suscetibilidades aos impactos ambientais. Identificou-se que o grau de vulnerabilidade máximo corresponde somente a $0,01 \%$ da área total amostrada. Sugere-se recuar as atividades para fora das áreas frágeis identificadas na linha de costa, para maximizar a resiliência destes ambientes e reduzir os efeitos do avanço do mar.

Palavras-chave: Erosão. Mata Atlântica.Vulnerabilidade. Porto Seguro.

\section{The Discovery Museum in the Bahia, Brasil:geosystem and environmental vulnerability}

Aвstract - This article aims to analyze the Geosystem of the Open Discovery Museum, in order to measure its environmental vulnerability. Specifically, characterize the biotic, physical and socioeconomic environment; draw up a map of relative environmental vulnerability and suggest changes in uses based on the National Policy on Climate Change. The area has been classified as historical heritage by IPHAN since 1996 and occupies the municipalities of Santa Cruz Cabrália, Porto Seguro and Prado in Bahia. Tourism is the main activity of the service sector. It was used a descriptive approach of the environments from maps and secondary data, having as theoretical contribution the Geosystems Theory. The vulnerability map was drawn from the overlap of thematic maps in the Arcgis GIS 10.1, cartographic information was rasterized and its attributes reclassified. Degrees of vulnerability were attributed to each component of physical environmental factors, according to their susceptibilities to environmental impacts. It was identified that the maximum degree of vulnerability corresponds to only $0.01 \%$ of the total area sampled. It is suggested that activities outside the fragile areas identified on the coastline should be withdrawn to maximize the resilience of these environments and reduce the effects of the sea's advance.

Keywords: Erosion. Atlantic Forest of Brazil. Vulnerability. Porto Seguro. 


\section{Museo Abierto de lo Descubrimiento en Bahía, Brasil: geosistema y la vulnerabilidad ambiental}

Resumen - Este artículo tiene como objetivo analizar el Geosistema del Museo Abierto del Descubrimiento para medir su vulnerabilidad ambiental. Específicamente, caracterizar el medio biótico, físico y socioeconómico; elaborar un mapa de vulnerabilidad ambiental relativa y sugerir cambios de usos con base en la Política Nacional sobre Cambio Climático. El área se considera como patrimonio histórico por el IPHAN (1996) y ocupa los municipios de Santa Cruz Cabrália, Porto Seguro y Prado en Bahía. El turismo es la principal actividad del sector de servicios. Se utilizó un enfoque descriptivo de los ambientes a partir de mapas y datos secundarios, teniendo como aporte teórico la Teoría de los Geosistemas. El mapa de vulnerabilidad fue elaborado a partir de la superposición de mapas temáticos en el SIG Arcgis 10.1, las informaciones cartográficas fueron rasterizadas y sus atributos reclasificados. Se asignaron grados de vulnerabilidad para cada componente de los factores físicos ambientales, según sus susceptibilidades a los impactos ambientales. Se identificó que el grado de vulnerabilidad máximo corresponde solamente al 0,01\% del área total muestreada. Se sugiere retroceder las actividades hacia fuera de las áreas frágiles identificadas en la línea de costa, para maximizar la resiliencia de estos ambientes y reducir los efectos del avance del mar.

Palabras clave: Erosión. Bosque Atlántico de Brasil. Vulnerabilidad. Porto Seguro.

\section{INTRODUÇÃO}

A geografia turística da Bahia, pode ser melhor compreendida a partir de suas 3 (três) fases de planejamento promovido pelo Estado. De 1934-1969 foi marcada pela construção da identidade turístico-cultural, a segunda fase de 1970-2006 contou com a implementação de infraestrutura básica e turística direcionado a destinos alvos de alto valor histórico e ambiental, e a terceira fase de 2007-2016 direcionado a qualificar e inovar os destinos buscando a integração econômica (Bahia 2011).

Nas duas últimas fases, o Estado organizou o território dividindo-o em zonas de forma a agrupar os municípios com "vocação" turística ressaltando os recursos naturais, culturais e históricos apresentando planos e programas de ação para o desenvolvimento do turismo. Porém, o desconhecimento das ferramentas de planejamento e gestão em âmbito municipal pelos gestores, não conseguia desenvolver, na prática, o turismo com bases na sustentabilidade social, ambiental e econômica (Carvalho 2008).

Para este estudo, o Turismo será considerado como um fenômeno social de natureza espacial (Palomeque 2003), caracterizado por uma demanda flutuante, que afeta diversos setores produtivos, como transporte, hotelaria, alimentos e bebidas, comércio, artesanato, entretenimento, entre outros. Importante esclarecer que o turismo não é um setor da economia (Faria 2007), e sim uma das atividades do setor terciário.

Nesta complexidade, o município que tenha "vocação" ou queira buscar desenvolverse a partir desta atividade, deve avaliar os recursos naturais e culturais disponíveis, prever os possíveis impactos, propor ações a serem implantadas e revisar ao longo do tempo este planejamento, pois este fluxo de pessoas também se beneficia de recursos não transacionais ${ }^{1}$ (Faria 2007), juntamente com os seus residentes promovendo mudanças diferenciadas a cada ano. Desta forma, não se compreende o estímulo deste fenômeno sem ter bases sólidas na gestão pública, privada, comunitária e também de terceiro setor, bem como a integração sistêmica de Secretarias respeitando a resiliência dos recursos naturais disponíveis no local.

Gerir um território com múltiplos interesses não é uma tarefa fácil, além disso, considerar que as alterações nos diferentes componentes da natureza quebram o equilíbrio dinâmico do ecossistema (Sporl e Ross 2004) tem sido o grande desafio dos estudos que tentam medir a resiliência dos ambientes frente às ações antrópicas.

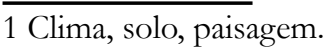


No que se refere ao Museu Aberto do Descobrimento (MADE) situado na Costa do Descobrimento e Costa das Baleias, segundo o zoneamento turístico da Bahia (Brasil 2016), este carece de uma avaliação de vulnerabilidade ambiental por conta da pressão antrópica que vem sofrendo ao longo da sua história de uso e ocupação. Seu acervo é composto por um conjunto de acidentes geográficos e núcleos urbanos tradicionais, dispostos como peças em exposição permanente, tendo o turismo, como atividade mais explorada na área. $\mathrm{O}$ turismo estimulado pelo Estado, especificamente com o Programa de Desenvolvimento do Turismo do Nordeste (PRODETUR) modificou a paisagem com a criação da rodovia BR-367, assim como fomentou a implantação dos meios de hospedagem, serviços de alimentação como barracas de praia e restaurantes, por toda a zona costeira.

Para tanto, considerou-se utilizar como referência teórica o Geossistema de Tricart (1977) para que os elementos que compõem a área de estudo possam ser levados em consideração e a Política Nacional sobre Mudanças do Clima (Brasil 2009), que indica e orienta ações da gestão pública para as mudanças do clima e seus possíveis impactos no país.

Assim, o estudo tem como objetivo principal, analisar o Geossistema do Museu Aberto do Descobrimento (MADE) e de sua área de influência (AI), sendo considerada a área total do território de cada município em que o MADE está inserido, de forma a medir suas vulnerabilidades ambientais. Especificamente, a) caracterizar o meio biótico, físico e socioeconômico; b) elaborar um mapa de vulnerabilidade ambiental relativa; c) sugerir mudanças de usos com base na Política Nacional sobre Mudanças do Clima (2009).

\section{Material e métodos}

Area de Estudo

O Museu Aberto do Descobrimento foi criado pelo Decreto no 1.874, de 22 de abril de 1996 legitimando a primeira descrição geográfica do Brasil, tendo como diretriz a conservação, promoção e exploração por meio do turismo qualificado, os elementos históricos, culturais e naturais do sítio, com a participação dos residentes (BRASIL 1996). Corresponde a uma área de 147.639 hectares, com $130 \mathrm{~km}$ de praia envolvendo os municípios de Santa Cruz Cabrália, Porto Seguro e Prado, na Bahia, Figura 1. 
Figura 1. Localização dos municípios de Santa Cruz Cabrália, Porto Seguro, Prado e sobreposição do MADE, no extremo sul do Estado da Bahia.

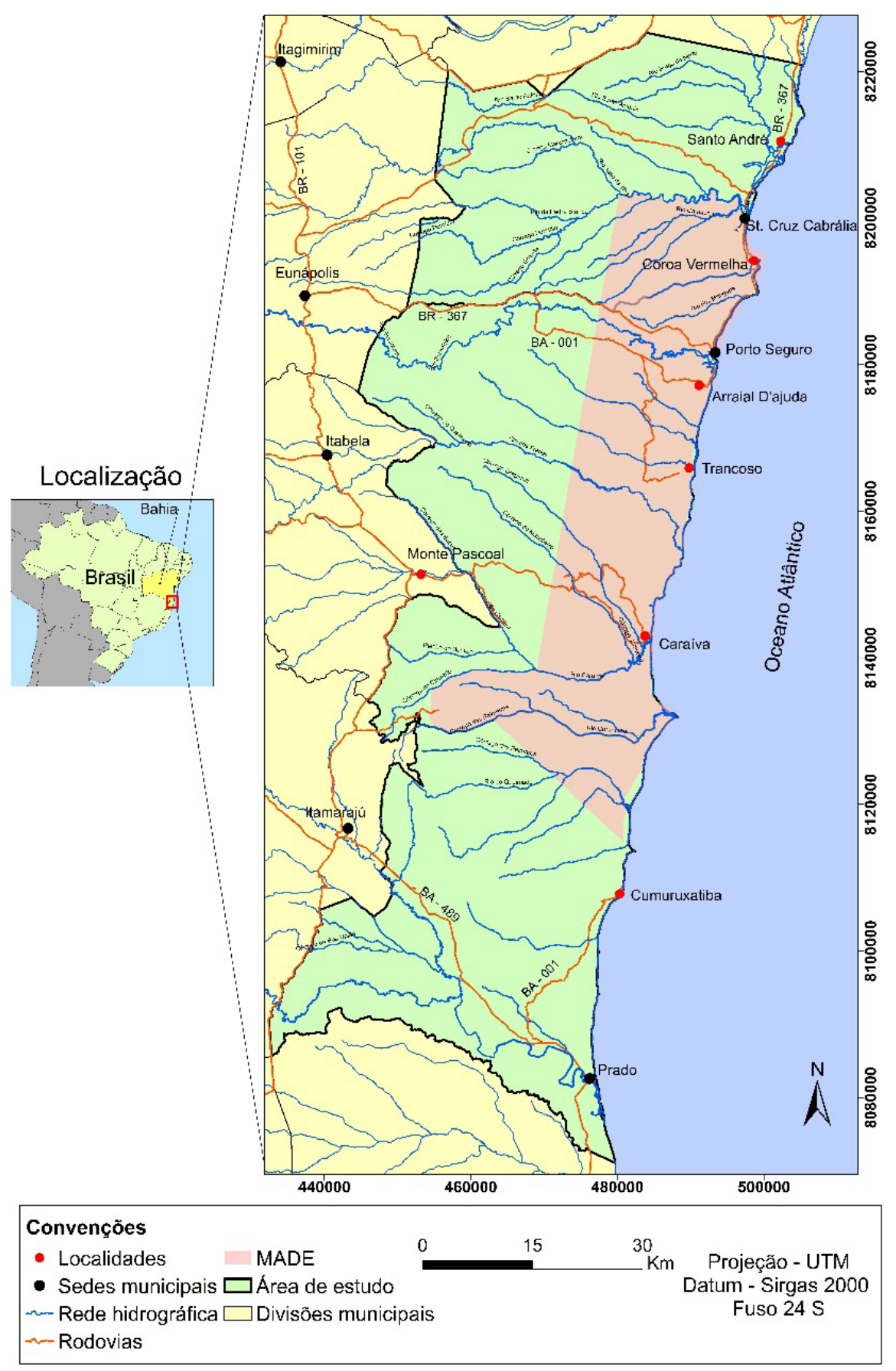

Fonte: DERBA (Rodovias), Bahia SEI (Limites municipais, MADE, hidrografia, sedes municipais e localidades).

Para uma análise geossistêmica, observa-se a necessidade de compreender o ambiente natural, as interferências antrópicas ao longo do período histórico para que se possam avaliar os sistemas que influenciam direta eindiretamente no sistema do MADE. Para tal, utilizam-se os limites definidos pelo Instituto do Patrimônio Histórico e Artístico Nacional (IPHAN), como:

Desde a foz do Rio João de Tiba, ao norte, (Marco 1) até a Ponta de Imbaçuaba, ao sul (Marco 2); desse ponto na direção noroeste, até a confluência do Rio Corumbau com o Córrego das Palmeiras (Marco 3); daí prossegue pela divisa do Parque Nacional do Monte Pascoal, nas direções oeste, norte e leste, até a confluência do Córrego do Cemitério com o Rio Caraiva (Marco 4); seguindo, na direção norte, até o RN 119, junto à Rodovia BR-387 (Marco 5); de onde prossegue 
na direção oeste pela Rodovia BR-367 até o RN 118, próximo ao quilômetro 41 da mesma Rodovia (Marco 6); continua, na direção norte, até a confluência do Rio das Pedrinhas com o Rio João de Tiba (Marco 7); prosseguindo pelo Rio João de Tiba, a jusante, até a foz, fechando o perímetro (Brasil, Decreto Lei ${ }^{\circ} 1874$ de 22/04/1996).

Os municípios têm características de uso e ocupação bem peculiares apesar da sua proximidade. Porto Seguro é o marco do "Achamento ${ }^{2}$ do Brasil" (Iglesias 1992; Silva 2002) está inserido na zona Turística - Costa do Descobrimento (Brasil 2016), faz parte dos 65 destinos indutores do turismo no Brasil (Brasil 2008), possui o maior adensamento de Unidades de Conservação (UC) da costa brasileira (Santos e Schiavetti 2014), tombado pelo IPHAN em 1973 (Brasil, Decreto no 72.107/73) e reconhecido pela UNESCO como Patrimônio Natural da Humanidade, detém 52\% da população indígena da Bahia (Velame, 2010) e classificado como uma Key Biodiversity Area $-\mathrm{KBA}^{3}$ (Paese et al. 2010). O município depende economicamente do turismo, tendo em vista que esta atividade responde a 76,4\% do PIB do município (IBGE 2016), colocando-o numa posição de dependência e que deve ter uma atenção diferenciada pelos gestores.

O município de Santa Cruz Cabrália tem a cidade histórica tombada pelo IPHAN, assim como o Ilhéu de Coroa Vermelha onde foi celebrada a primeira missa no Brasil (Arantes 2001). No que se refere ao setor de serviços sua dependência é menor que Porto Seguro, mas ainda assim alta, corresponde a 67\% do PIB, seguido $21 \%$ na agricultura e $12 \%$ na indústria (IBGE 2014).

Prado destaca-se pela exploração de metais pesados (ilmenita, zirconita e monazita) na soleira das falésias e no interior, plantação de eucalipto (Amorin e Oliveira 2007). Seu PIB é representado pela agricultura (54\%), 39\% setor de serviços e $7 \%$ indústria.

\section{Métodos e técnicas}

Utilizou-se a pesquisa bibliográfica e documental para caracterizar o meio físico, biótico e socioeconômico dos municípios que compõem a área de estudo. Esses dados foram coletados e interpretados a partir de mapas temáticos (declividade, pluviosidade, idade geológica, pedologia, uso e ocupação do solo), além de dados secundários disponíveis no censo demográfico do IBGE para cada município. Desta forma, foi possível correlacionar os indicadores socioeconômicos (densidade demográfica, população ocupada, IDH etc) com a vulnerabilidade ambiental encontrada no mapa, baseado na Teoria dos Geossistemas (Tricart 1977).

Para a elaboração do mapa de vulnerabilidade da área foi utilizado uma análise multicritério, que envolveu o cruzamento de atributos físicos-ambientais e antrópicos (uso e ocupação da área), representado pelos mapas temáticos já citados acima. Este processo é apresentado na Figura 2, sintetizando as principais etapas da análise multicritério.

A partir do mapa de vulnerabilidade relativa, identificaram-se áreas de maior e menor vulnerabilidade de forma a sugerir novas práticas frente à Política Nacional de Mudanças Climáticas.

2 Termo utilizado na Carta de Pero Vaz de Caminha Disponível em< http://objdigital.bn.br/Acervo_Digital/Livros_eletronicos/carta. pdf $>$.

3 Áreas chaves para a conservação da Biodiversidade - Parque Nacional Monte Pascoal, Pau Brasil e RPPN Veracel. 
Figura 2. Fluxograma dos procedimentos metodológicos para a criação do mapa de Vulnerabilidade relativa

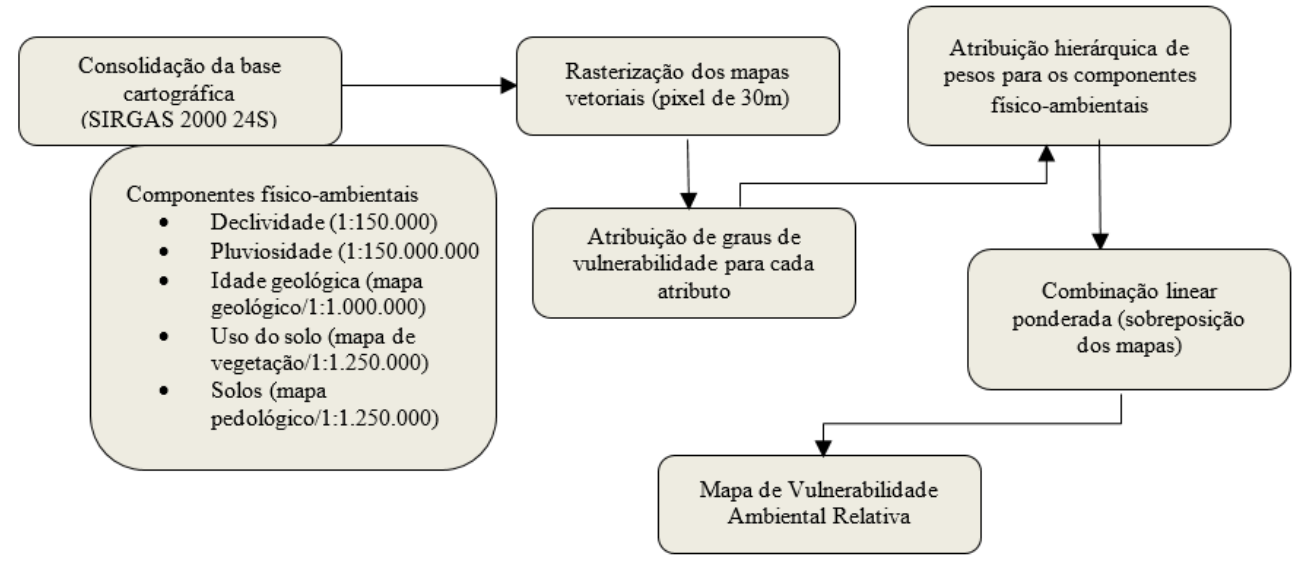

Para avaliar e agregar os vários critérios ambientais foi adaptado à metodologia proposta por Tagliani, (2003), Sporl e Ross (2004), que utiliza o método de combinação linear ponderada de forma a relacionar os componentes: solo, declividade, vegetação, recursos hídricos, e idade, atribuindo-os pesos e graus de vulnerabilidade variando de 1 a 5, de acordo com a classificação dos atributos de cada componente. Para o processamento dos dados, foram considerados os mesmos pesos para os componentes definidos por Tagliani (2003), em função do grau de importância que eles exercem no todo e optou-se por substituir o fator "recursos hídricos" pelo fator "pluviosidade", em função da abrangência espacial que este dado apresenta para a área em questão.

De acordo com Tagliani (2003), o critério de maior importância na hierarquização dos componentes físicoambientais é à fragilidade estrutural intrínseca representado pelos fatores declividade e solos. Ambos têm uma relação mais direta com o processo erosivo e são capazes de provocar maiores alterações no substrato físico, potencializando a vulnerabilidade ambiental. Em segundo lugar, o critério sensibilidade é representado pelos fatores: cobertura vegetal (uso e ocupação do solo) e recursos hídricos (substituído pelo fator pluviosidade), e é condicionada pela proximidade dos ecossistemas sob proteção legal. Por último, o critério grau de maturidade dos ecossistemas (fator idade geológica), representa o tempo de evolução do substrato geológico frente aos distúrbios antrópicos. A atribuição dos pesos foi baseada na técnica de comparação pareada, considerando a importância relativa de cada componente para a vulnerabilidade ambiental, sendo que cada elemento da matriz indica quanto o fator da coluna da esquerda é mais importante que o fator correspondente na linha superior, Tabela 1.

Tabela 1. Comparação pareada dos fatores físico ambientais na determinação dos pesos.

\begin{tabular}{crrrrr}
\hline Fatores & Pluviosidade & Declividade & Solos & Uso do solo & Idade geológica \\
\hline Pluviosidade & 1 & & & & \\
Declividade & 3 & 1 & & & \\
Solos & 3 & 1 & 1 & 1 & \\
Uso do solo & 1 & $1 / 3$ & $1 / 3$ & $1 / 3$ & 1 \\
Idade geológica & $1 / 3$ & $1 / 3$ & $1 / 3$ & & \\
\hline
\end{tabular}

Fonte: Adaptado de Tagliani (2003).

A definição dos graus de vulnerabilidade de cada atributo que compõe os componentes físico-ambientais foi baseada na maior ou menor predisposição do atributo ao impacto potencial ambiental, de modo que quanto maior for o grau de vulnerabilidade, maior será o impacto associado. Como os mapas temáticos (em formato de imagem), são compostos por pixels, cada pixel carrega um atributo, como exemplo, a componente declividade é composto por quase 6 milhões de pixels (atributos) classificados em três classes (0-10\%, 10 a 45\% e >45\%), para os demais componentes, a classificação de seus atributos varia de 3 a 5 classes, conforme apresentado na Tabela 2. 
Tabela 2. Determinação dos parâmetros para avaliação da vulnerabilidade ambiental para a área compreendida entre os municípios de Santa Cruz Cabrália, Porto Seguro e Prado, na Bahia.

\begin{tabular}{|c|c|c|c|}
\hline Fator & Atributo & Peso & $\begin{array}{l}\text { Grau de vulnerabilidade } \\
\text { ambiental }\end{array}$ \\
\hline \multirow{3}{*}{$\begin{array}{l}\text { Declividade } \\
\qquad \%)\end{array}$} & $0-10$ & \multirow{3}{*}{0,3262} & 1 \\
\hline & 10 e 45 & & 3 \\
\hline & $>45$ & & 5 \\
\hline \multirow{3}{*}{$\begin{array}{l}\text { Pluviosidade } \\
\qquad(\mathrm{mm} / \mathrm{h})\end{array}$} & 0,132622 & \multirow{3}{*}{0,1370} & 1 \\
\hline & 0,135145 & & 3 \\
\hline & 0,141151 & & 5 \\
\hline \multirow{5}{*}{ Idade geológica } & Mesoarqueano & \multirow{5}{*}{0,0736} & 1 \\
\hline & Toniano & & 2 \\
\hline & Quaternário & & 3 \\
\hline & Oligoceno & & 4 \\
\hline & Holoceno & & 5 \\
\hline \multirow{5}{*}{$\begin{array}{c}\text { Uso e } \\
\text { ocupação do } \\
\text { solo }\end{array}$} & Floresta primária & \multirow{5}{*}{0,1370} & 1 \\
\hline & Floresta secundária & & 2 \\
\hline & Reflorestamento / Restinga & & 3 \\
\hline & Agricultura/Pecuária & & 4 \\
\hline & Áreas úmidas/Área urbana & & 5 \\
\hline \multirow{5}{*}{ Solos } & $\begin{array}{c}\text { Latossolo amarelo / vermelho amarelo } \\
\text { distróficos }\end{array}$ & \multirow{5}{*}{0,3262} & 1 \\
\hline & $\begin{array}{c}\text { Argissolo amarelo / vermelho amarelo } \\
\text { distróficos }\end{array}$ & & 2 \\
\hline & Cambissolo háplico & & 3 \\
\hline & $\begin{array}{c}\text { Neossolo quartzarênico / Espodossolo } \\
\text { hidromórfico / }\end{array}$ & & 4 \\
\hline & Gleissolo háplico & & 5 \\
\hline
\end{tabular}

Fonte: Adaptação de Tagliani, (2003), Sporl e Ross (2004), base de dados IBGE, INEMA, NASA, USGS.

Os dados pluviométricos foram obtidos através de instrumentos da missão (TRMM-Tropical Rainfall Measuring Mission, produto 3B42), que fornecem a taxa pluviométrica $\mathrm{em} \mathrm{mm} / \mathrm{h}$ a partir de técnicas de sensoriamento remoto. Apresentam células com resolução espacial de 0,25 (aproximadamente $30 \mathrm{~km}$ ) e resolução temporal de 3 horas, disponíveis na plataforma Giovanni vinculada à Agência Espacial Americana - NASA (Kummerow et al. 2000; NASA 2015). Tais dados, correspondente ao período de 18 anos (1998-2016), em formato Network Common Data Form (netCDF), foram convertidos para formato raster (matricial), com tamanho de pixel de 30 metros, com os quais calculou-se a média do período considerado em unidade de $\mathrm{mm} / \mathrm{h}$ através da técnica de álgebra geográfica (Spatial analyst tools/Map Algebra) do SIG ArcGIS 10.1.

Assim, procedeu-se a manipulação da base cartográfica oriunda de organizações governamentais (Instituto Brasileiro de Geografia e Estatística - IBGE, United States Geological Survey - USGS, National Aeronautics and Space Administration - NASA e Instituto do Meio Ambiente e Recursos Hídricos - INEMA os quais forneceram as informações físico-ambientais da região, disponíveis em mapas temáticos em formato vetorial, como os de Solos e uso e ocupação do solo (INEMA, escala 1: 1.250.000), Idade geológica a partir do mapa geológico da Bahia (IBGE, escala 1: 1.000.000) e formato matricial: Declividade (USGS, modelo digital de elevação, oriundo da missão SRTM com 30 m de resolução espacial) e pluviosidade (NASA, dados TRMM 3B42, pixel convertido para tamanho de $30 \mathrm{~m})$.

Tais dados foram processados no Sistema de Informação Geográfica (SIG) Arcgis 10.1 na projeção cartográfica Universal Transversa de Mercartor (UTM), datum Sirgas 2000, fuso 24 S, onde aqueles em formato vetorial foram 
convertidos para formato raster através do algoritmo feature to raster (pixel 30 x 30m), com o intuito de nivelar as informações em formato matricial e possibilitar a análise multicritério por meio da combinação ponderada. Nesse ambiente SIG, a atribuição dos graus de vulnerabilidade para cada atributo componente dos fatores físicoambientais foi realizada mediante reclassificação dos arquivos raster (Spatial analyst/Reclass/Reclassify).

A técnica de combinação linear ponderada foi implementada através da sobreposição dos atributos em função dos pesos de cada componente (Spatial analyst/Ovarley/Weighted overlay), produzindo o mapa de vulnerabilidade ambiental relativa com graus variando de 1 a 5 . Os graus de vulnerabilidade por área foram submetidos ao teste não paramétrico de Kruskal Wallis (KW, nível de confiança de $95 \%$, p <0,05) a fim de comparar possíveis diferenças entre as unidades territoriais consideradas e entre as vulnerabilidades dentro de cada uma das unidades.

\section{RESUltados}

\section{Caracterização dos meios biótico, físico e socioeconômico}

O extremo sul da Bahia está sob o domínio da Mata Atlântica, com fragmentos de floresta secundária em estágio inicial, médio e avançado de regeneração, além de poucos fragmentos em estágio primário, representados por parte dos Parques Nacionais (PARNA) do Pau Brasil, Monte Pascoal e da RPPN Estação Veracel (Sette 2013). As 3 (três) Unidades de Conservação (UC) de sistema terrestre mais relevantes. Nessa região, este Bioma apresenta grande variedade de ecossistemas associados de grande importância biológica, como as mussunungas, brejos, restingas e floresta aluvial (floresta ombrófila densa de terras baixas, também conhecida como mata paludosa), além dos manguezais.

Os maiores blocos de mussunungas encontra-se em Porto Seguro entre Itaporanga/Caraíva. Os de restinga arbórea e arbustiva em Trancoso e Caraíva, e no distrito sede de Porto Seguro encontra-se o ambiente mais antropizado inclusive com espécies exóticas invasoras, como a Leucena (Leucaena leucocephala) e amendoeira (Terminalia catappa L.). Segundo dados do INEMA (2014) na área de estudo, os brejos ocupam 5,39\% do território e estão associados às calhas fluviais dos rios Buranhém, Caraíva, dos Frades e Jucuruçú. Padrão semelhante ao dos manguezais $(0,51 \%$ da área) que ocupam exclusivamente os estuários dos rios supracitados acima, além dos rios João de Tiba e Corumbau. As restingas que ocupam 2,30\% da área são mais expressivas na faixa litorânea entre Santa Cruz Cabrália e Porto Seguro, a partir do estuário do rio Buranhém distribuem-se descontinuamente como fragmentos associados aos mais variados ambientes, desde os mais conservados aos mais predatórios, como a classe agropecuária, predominante em toda a área de estudo (54,25\%). As florestas secundárias que ocupam 13,26\% do território são menos abundantes que as florestas primárias (17,64\%) que estão concentradas sobre tudo nos Parques Nacional (PARNA) do Pau Brasil e no PARNA do Monte Pascoal, apesar de estarem imersas sobre a matriz predominantemente agropecuária.

Quanto ao clima, se enquadra totalmente no tipo Af - chuvoso quente e úmido, característico da região litorânea, envolvendo uma faixa de $50 \mathrm{~km}$ de largura, com precipitações elevadas (Peel et al. 2007), e chuvas bem distribuídas ao longo do ano chegando até $1.592 \mathrm{~mm}$ /ano. Os meses mais chuvosos são abril, maio, outubro, novembro e dezembro, e a temperatura média anual chega a $24,0{ }^{\circ} \mathrm{C}$. Os dados TRMM (3B42) considerando a média do período entre 1998 e 2016, indicam maiores precipitações $(0,1411 \mathrm{~mm} / \mathrm{h})$ ao longo da faixa litorânea, as mais baixas $(0,1326 \mathrm{~mm} / \mathrm{h})$ distribuem-se em direção ao interior com pequenas variações das lâminas precipitadas. Destacamos a insuficiência de dados pontuais para o monitoramento da área sobre o clima, pois apenas Porto Seguro dispõe uma estação meteorológica automática localizada na Ceplac (posição $16^{\circ} 27^{\prime} \mathrm{S}$ e $39^{\circ} 4^{\prime} \mathrm{W}$ ) aberta em 10/07/2008 e monitorada pelo INMET, de forma que os estudos são realizados com a base de dados coletados em Estações Convencionais localizadas nos municípios de Guaratinga (1973) e Caravelas (1930), além de auxílio de dados da INFRAERO localizado no aeroporto (1982) de Porto Seguro. Para tal, as projeções realizadas para os 
anos de 2020, 2050 e 2080 (Porto Seguro, 2014, p.63-65) indicam uma tendência de incremento da precipitação e aumento da temperatura de até $2,3^{\circ} \mathrm{C}$ para 2050.

Quanto a formações geológicas destacam-se o Grupo Barreiras, os depósitos flúvio-lagunares e os sedimentos do quaternário (depósitos litorâneos indiferenciados recentes) (Dantas et al 2002; Amorin e Oliveira 2007). Segundo dados do mapa geológico do IBGE (escala 1: 1.000.000), o grupo barreiras predomina sob toda a área de estudo, ocupando mais de 70\% do território, de época holocênica, são compostos por sedimentos clásticos (arenito e argilito) e distribuem-se por toda porção interiorana, intercalados pelas coberturas detríticas indiferenciadas as quais representam a unidade mais proeminente após o grupo barreiras, de período quaternário, essas coberturas também são compostas pelos sedimentos inconsolidados. O grupo Jequitinhonha $(6,21 \% \mathrm{da}$ área) terceira categoria mais abundante, difere das demais, pela composição por litotipos mais resistentes (gnaisses, quartzitos, dentre outros tipos) e idade mais antiga (período Toniano), ocupam os terrenos mais elevados e declivosos no extremo oeste da região.

Os dados do mapeamento de solos do INEMA (escala de 1:1.250.000), apontam que os principais tipos de solo são os Latossolos amarelos distróficos, Argissolos amarelos distróficos e os Gleissolos háplicos, ocupando cerca de $72 \%, 15 \%$ e $6 \%$ da área de estudo respectivamente. Os Latossolos, que são pouco férteis para a agricultura sendo necessário uso de fertilizantes e corretivos, distribuem-se expressivamente no interior associados ao grupo barreiras, os Argissolos ocupam a grande parte da faixa costeira do município de Prado, próximos às desembocaduras dos principais rios da região e em menor parte, porções do grupo Itapetinga no noroeste do município de Santa Cruz Cabrália, já os Gleissolos, as áreas de brejos associados às calhas fluviais e nos vales bem esculpidos dos rios Santo Antônio e João de Tiba sob as pequenas porções do grupo Itapetinga. Esse tipo de solo expõe alta fragilidade em razão de seu pouco desenvolvimento e lençol freático superficial (Franco et al. 2011).

Quanto à geomorfologia do município, destacam-se os tabuleiros costeiros, planícies costeiras e chãs prélitorâneas. Os tabuleiros costeiros ocorrem em uma extensa faixa norte-sul ao longo de toda a costa, onde se encontra a grande parte das atividades agropecuárias do município. Estes tabuleiros formam falésias ativas, mais presentes em Arraial D’Ajuda e Trancoso distritos de Porto Seguro e em Prado, em que alguns trechos dificultam o acesso à praia e a ocorrência de blocos ou promontórios. É comum não existir praia recreativa, durante a preamar, ao longo desses trechos (Reimão 2008). Outro fator marcante na região é a presença de recifes de corais e bancos de arenitos, em geral expostos nos períodos de maré baixa. Estes protegem uma parte das praias das ondas, de forma que, em alguns trechos pode se perceber áreas susceptíveis a acumulação, arrebentação e em outras, a erosão. Destaque para o Parque Municipal Marinho do Recife de Fora que no início de 2016 foi aprovado o seu plano de Manejo e uso recreativo pelo turismo náutico.

A ocupação do extremo sul passou por sucessivas transformações sociais e econômicas decorrentes da exploração dos recursos naturais e ocupação de terras para agricultura, pecuária e turismo. Seu primeiro ciclo econômico foi caracterizado pela intensa exploração da madeira da Mata Atlântica, entre elas o Pau Brasil, seguidas já no século XIX pelo plantio de café e cacau (Teixeira et al. 2006). Apesar da dinâmica produtiva local, as explorações agrícolas eram temporárias e inexpressivas, resultantes de núcleos de povoamento do litoral, sem integração regional (CEI 1992).

A partir da década de 50 as transformações socioeconômicas da região imprimiram uma nova dinâmica local. A região integrou-se a economia estadual e nacional facilitada pela implantação da Rodovia Federal BR 101, que estimulou o desmatamento da vegetação nativa facilitando a extração de madeira em serrarias, reconfigurando o ordenamento político do espaço, resultando na criação de novos municípios e perda de área para outros, sendo percebidos mais facilmente na década de 1970 com o seu asfaltamento.

$\mathrm{Na}$ década de 1990, o Estado recebe investimentos para o turismo, configurando nos três municípios uma nova estética composta de estradas, aeroporto, infraestrutura de lazer, ocupação das praias por barracas e equipamentos de recepção turística, além do processo de patrimonialização dos centros históricos. Neste mesmo período, é concedida a implantação das empresas de papel e celulose Veracel, Bahia Sul e Aracruz possibilitando o desenvolvimento da indústria e plantação de eucalipto na região (Carneiro 1994; Pedreira 2004). 
No ano 2000, durante a comemoração dos 500 do Brasil a área se transforma num espaço de disputa de uso e ocupação de terras, entre turismo, patrimônio, indígenas e favelização. A atração de pessoas em busca de emprego pela cadeia produtiva do turismo tem aumentando o número de residentes na área urbana, o que tem causado até os dias atuais, problemas socioeconômicos para a gestão municipal.

Baseado nos dados dos últimos censos do IBGE pode-se observar que os municípios apresentam números diferenciados de indicadores socioeconômicos, mesmo estando tão próximos e legalmente registrados como área de desenvolvimento conjunto, conforme a Tabela 3.

O crescimento da população é identificado nos três municípios, sendo que Santa Cruz Cabrália e Porto Seguro o crescimento foi três vezes maior considerando 1991 a 2000. O grau de urbanização é menor em Prado e maior em Porto Seguro no ano de 2010. No que se refere ao Índice de Desenvolvimento Humano Municipal (IDHM) em 1991 os municípios obtiveram níveis considerados como muito baixos (PNUD 2013) e Prado o menor índice. Em 2010 os três municípios aumentam o valor do índice passando para a faixa de médio desenvolvimento. Porém esta classificação ainda é baixa considerando os municípios baianos em que, Prado ocupa o $84^{\circ}$ lugar, Santa Cruz Cabrália $40^{\circ}$ e Porto Seguro o $20^{\circ}$.

Tabela 3. Indicadores socioeconômicos dos municípios que compõem o MADE.

\begin{tabular}{rrrrrrrrrrr}
\hline \multicolumn{1}{c}{ Indicadores } & \multicolumn{3}{c}{ Santa Cruz Cabrália } & \multicolumn{3}{c}{ Porto Seguro } & \multicolumn{3}{c|}{ Prado } \\
\hline Área $\left(\mathrm{km}^{2}\right)$ & \multicolumn{3}{c}{$1.459,832$} & \multicolumn{3}{c}{$2.287,085$} & \multicolumn{3}{c}{$1.687,347$} \\
\hline Ano & 1991 & 2000 & 2010 & 1991 & 2000 & 2010 & 1991 & 2000 & 2010 \\
\hline População total & 6.535 & 23.888 & 26.264 & 34.661 & 95.721 & 126.929 & 22.632 & 26.498 & 27.627 \\
População Urbana & 3.197 & 13.527 & 19.002 & 23.315 & 76.619 & 104.078 & 9.655 & 14.169 & 15.474 \\
População Rural & 3.338 & 10.361 & 7.262 & 11.346 & 16.102 & 22.852 & 12.977 & 12.329 & 12.153 \\
Grau de & $48,9 \%$ & $56,6 \%$ & $72,3 \%$ & $67,8 \%$ & $83,2 \%$ & $82,0 \%$ & $42,7 \%$ & $53,5 \%$ & $56,0 \%$ \\
urbanização & & & & & & & & & \\
IDHM* & 0,344 & 0,486 & 0,654 & 0,367 & 0,495 & 0,676 & 0,298 & 0,471 & 0,621 \\
Renda (per capita) & 181,32 & 349,72 & 388,28 & 236,09 & 391,35 & 527,04 & 131,16 & 278,10 & 369,96 \\
\hline
\end{tabular}

Fonte: IBGE (1991), (2000), (2010).

*IDHM - Índice de Desenvolvimento Humano Municipal (PNUD, 2013).

Ainda de acordo com a Tabela 3, Porto Seguro ainda detém o maior número populacional concentrado na área urbana cinco vezes mais do que a população urbana de Santa Cruz Cabrália e Prado. Assim, como sua renda per capita é a maior entre os municípios.

\section{Vulnerabilidade ambiental do MADE e dos seus municípios}

Algumas pesquisas têm fundamentado suas propostas metodológicas na teoria geossitêmica, integrando diferentes tipologias de planos de informações, com o objetivo de identificar capacidades e restrições ambientais de determinadas unidades territoriais, como bacias hidrográficas, ecossistemas e regiões administrativas.

De forma geral, a adoção dos componentes ambientais: geologia, relevo, solos, uso e ocupação do solo e clima, e ou parte desses, são comumente utilizados por propostas de avaliação de vulnerabilidade ambiental (Tagliani 2003), fragilidade ambiental (Franco et al. 2011), zoneamento geoambiental (Santos et al. 2014), zoneamento agroecológico (Souza et al. 2012), fragilidade potencial natural e vulnerabilidade potencial a erosão (Spörl e Ross 2004), com escalas que variam de 1:50.000 a 1:100.000. Considerando esses atributos e componentes, obteve-se o Mapa de Vulnerabilidade Ambiental relativa do MADE e de seus municípios, conforme Figura 3. A partir deste mapa foi calculada a área correspondente de vulnerabilidade em seus graus (1 a 5) para cada município do MADE e a área total somando todos os municípios, conforme a Tabela 4. 
Figura 3. Mapa de Vulnerabilidade Ambiental Relativa de Porto Seguro, Santa Cruz Cabrália e Prado, destaque para o MADE.

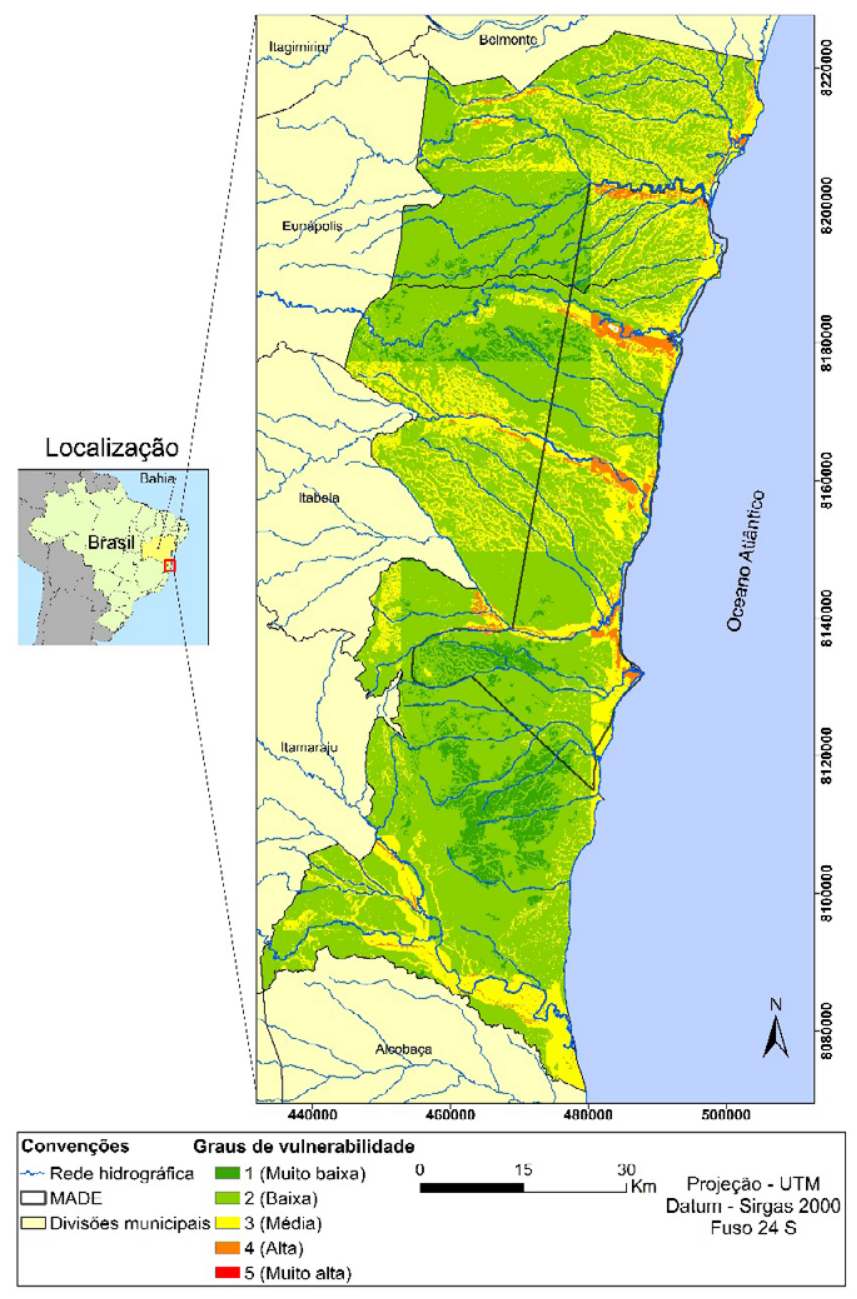

Fonte: Elaborado pelos autores, 2018.

Tabela 4. Vulnerabilidade ambiental relativa dos municípios de Santa Cruz Cabrália, Porto Seguro e Prado, bem como do MADE (área sobreposta) em hectares e percentagem

\begin{tabular}{|c|c|c|c|c|c|c|c|c|c|c|}
\hline \multirow{2}{*}{$\begin{array}{c}\text { Grau de } \\
\text { Vulnerabilidade }\end{array}$} & \multicolumn{2}{|c|}{ St. Cruz Cabrália } & \multicolumn{2}{|c|}{ Porto Seguro } & \multicolumn{2}{|l|}{ Prado } & \multicolumn{2}{|c|}{ MADE } & \multicolumn{2}{|c|}{ Área total } \\
\hline & $\begin{array}{c}\text { Cobertura } \\
\text { (ha) }\end{array}$ & $\%$ & $\begin{array}{c}\text { Cobertura } \\
\text { (ha) }\end{array}$ & $\%$ & $\begin{array}{c}\text { Cobertura } \\
\text { (ha) }\end{array}$ & $\%$ & $\begin{array}{c}\text { Cobertura } \\
\text { (ha) }\end{array}$ & $\%$ & $\begin{array}{c}\text { Cobertura } \\
\text { (ha) }\end{array}$ & $\%$ \\
\hline 1 & $3.398,85$ & 2,34 & $12.027,21$ & 5,29 & $18.064,77$ & 10,76 & $7.336,89$ & 4,97 & $33.492,24$ & 6,20 \\
\hline 2 & $98.164,59$ & 67,57 & $146.879,87$ & 64,66 & $116.488,99$ & 69,41 & $89.119,80$ & 60,36 & $361.564,38$ & 66,92 \\
\hline 3 & $40.981,57$ & 28,21 & $59.961,08$ & 26,40 & $31.890,68$ & 19,00 & $42.750,69$ & 28,96 & $132.839,10$ & 24,59 \\
\hline 4 & $2.730,67$ & 1,88 & $8.267,10$ & 3,64 & $1.360,92$ & 0,81 & $8.418,60$ & 5,70 & $12.358,89$ & 2,29 \\
\hline 5 & 7,47 & 0,01 & 24,21 & 0,01 & 17,37 & 0,01 & 12,87 & 0,01 & 49,05 & 0,01 \\
\hline Total & $145.283,15$ & 100 & $227.159,47$ & 100 & $167.822,72$ & 100 & $147.638,85$ & 100 & $540.303,66$ & 100 \\
\hline
\end{tabular}

Fonte: Elaborados pelos autores, 2018.

A partir da Figura 3 e da Tabela 4, constata-se que as áreas do MADE correspondente ao Grau 5 e 4 de vulnerabilidade são insipientes, (5,71\%). Entre os três municípios Porto Seguro tem o maior valor (3,64\%).

As áreas de Grau 5 (muito alta vulnerabilidade) são pouco significativas. Estão localizadas de forma descontínua, sempre adjacentes aos cursos d'água ou sob a calha fluvial destes, associadas em sua maioria aos sedimentos inconsolidados do quaternário e holoceno, ao grupo barreiras de idade oligocênica, sob gleissolos háplicos e terrenos de uso agropecuária com declividades maiores que $45 \%$ e precipitação média anual superior à $0,13 \mathrm{~mm} / \mathrm{h}$. Características geológicas também compartilhadas com as áreas de Grau 4 (alta vulnerabilidade), 
exceto as pequenas áreas sob terrenos metamorfizados do grupo Itapetinga no noroeste do município de Santa Cruz Cabrália, destacando-se a predominância de gleissolos háplicos, espodossolos hidromórficos e neossolos quartzarênicos, áreas de brejos e restingas sob declividades mínimas $(<10 \%)$ com precipitação média anual alta $(>$ $0,14 \mathrm{~mm} / \mathrm{h})$.

Em Santa Cruz Cabrália, na área identificada com Grau 4 (alta vulnerabilidade) encontram-se aldeamentos indígenas próximos ao leito dos rios, assim como instalações importantes para manutenção do fluxo turístico como o pequeno píer para embarcações que fazem a travessia no rio João de Tiba, tal como em Porto Seguro, na travessia da sede para o distrito de Arraial D’ajuda na foz do rio Buranhém.

Atenta-se que áreas de Grau 3 e 4 (média e alta vulnerabilidade) ocupam (34,66\%) da área do MADE, e Porto Seguro o município com maior porcentagem (30,4\%). Ocupam os interflúvios das drenagens da região e portanto, se sobrepõem-se sob boa parte das APPs marginais dos cursos d'águas, as quais apresentam déficit de cobertura florestal de 54\%, considerando-se a largura mínima de 30 metros para cada das margens fluviais (Brasil 2002), e cobertura florestal composta por florestas primárias, secundárias, reflorestamento e manguezais sendo essas últimas predominadas nos trechos finais da rede hidrográfica, nas zonas estuarinas.

Por outro lado, as áreas com Grau 2 (baixa vulnerabilidade) ocupam (66,9\%) considerando a média dos valores das divisões estabelecidas dentro da área integral, os três municípios e o MADE. Estão associados aos interflúvios tanto das pequenas drenagens, como dos cursos fluviais maiores, geralmente distantes da costa. Ocupam todas as tipologias geológicas, mas majoritariamente o grupo barreiras que predomina na região.

As áreas de Grau 2 (baixa vulnerabilidade) sobrepõem-se aos argissolos amarelos distróficos mais coesos e bem desenvolvidos, de mesmo modo, sob áreas de agropecuária nos municípios de Porto Seguro e Prado, assim como declividades medianas (entre 10 e 45\%) e precipitação média anual intermediária, em torno de 0,13 mm/h).

Os Parques Nacionais (PARNA) encontram-se sob os Graus 2 e 1 (baixa e muito baixa vulnerabilidade), enquanto que as Áreas de Proteção Ambiental (APAs) apresentam todos os graus de vulnerabilidade, mas ainda assim com pouca expressividade de áreas com Grau 4 e 5 (alta e muito alta vulnerabilidade).

De maneira geral, as classes mais suscetíveis a danos ambientais tanto de origem natural quanto antrópica, estão associadas aos terrenos desgastados e frágeis oriundos das contribuições da dinâmica marinha e fluvial, aliados a regimes pluviométricos excessivos, destacando-se dois pontos constantes de erosão no município de Porto Seguro Figuras 4 e 5.

Geralmente são áreas de acumulação dispostas tanto nas calhas fluviais dos trechos finais dos rios, ou a eles associados, quanto ao longo da costa da área de estudo. Contudo, ocupam 6\% do território considerado, dado a sobreposição de componentes com atributos que exibem alta fragilidade, com elevado potencial para dano ambiental.

Figura 4. Praia de Ponta Grande

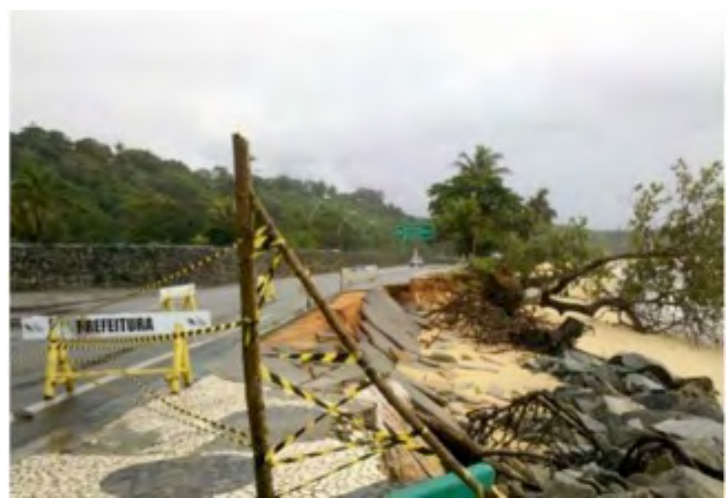

Fonte: Agazetabahia, 2014
Figura 5. Praia do Cruzeiro

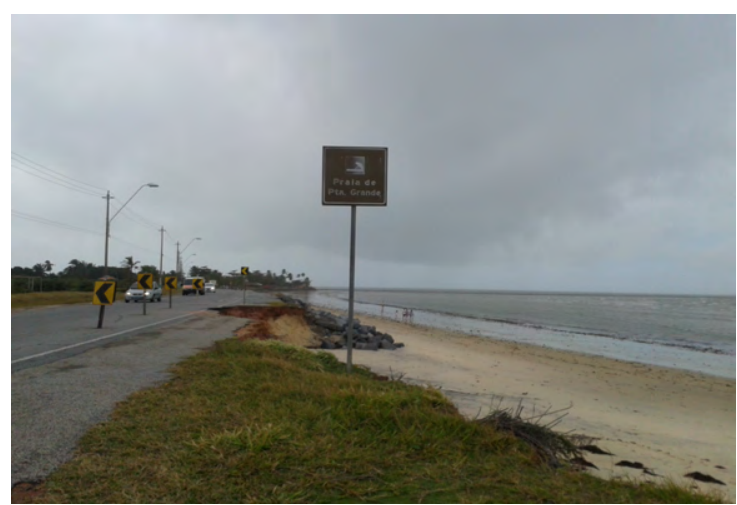

Fonte: Arquivo pessoal dos autores, 2017 
O teste de Kruskal Wallis não apontou diferenças entre as quatro unidades territoriais quanto aos graus de vulnerabilidade, (Kruskal-Wallis chi-squared $=0.1036, \mathrm{df}=3, \mathrm{p}$-value $=0.9914)$. No entanto, existem diferenças internas a respeito dessas vulnerabilidades, (Kruskal-Wallis chi-squared $=17.7333, \mathrm{df}=4$, $\mathrm{p}$-value $=0.001391$ ). De maneira geral, as variações dos graus de vulnerabilidade inerentes a cada unidade territorial seguem o mesmo padrão para a área integral, com predomínio das áreas de baixa vulnerabilidade, seguido pelas áreas de média e muito baixa vulnerabilidade e por último, as de muito alta vulnerabilidade.

\section{Discussão}

A devastação da Mata Atlântica, o uso inadequado do solo, o crescimento populacional acelerado, a expansão urbana e agrícola e a consolidação dos empreendimentos industriais e turísticos têm intensificado as desigualdades socioespaciais e a fragilidade ambiental natural no extremo sul da Bahia (Amorin e Oliveira 2007). Estes fatos puderam ser observados pelos mapas temáticos analisados no estudo e pelo mapa de vulnerabilidade relativa gerado, de forma que, identificou-se áreas com maior grau de vulnerabilidade nas APP's e áreas de restinga próximas à praia em todo o litoral do MADE.

Essa mesma área é ocupada por empreendimentos turísticos (hotéis, barracas de praia, estrada, casas de veraneio, bares e restaurantes) responsáveis por quase $80 \%$ do PIB da área, além de ter uma população flutuante que chega a variar de 3 a 5 vezes o número de residentes locais. Por outro lado encontra-se também percentuais de 9\% a 21\% de população ocupada, números relativamente baixos considerando a média nacional em 2016 (IBGE 2016). Estes índices aumentam a vulnerabilidade dos ambientes no local, tendo em vista que a população migra para áreas não urbanizadas nos municípios ocupando áreas com vegetação em regeneração, descortinando o solo. Constata-se também o crescimento da população urbana de forma exponencial nos municípios e principalmente em Porto Seguro, o que afeta diretamente no aumentando do consumo de água, energia, usos de estruturas de saúde e geração de resíduos.

Desta forma os municípios localizados na Zona Costeira considerados como áreas frágeis (Brasil 2009) devem conhecer as suas vulnerabilidades adaptando-se aos fatores das alterações climáticas iminentes de forma a gerir com maior eficácia a área. Porém o município por algum motivo, consentiu a implantação de infraestrutura turística ao longo da faixa praial, mesmo com os decretos de gerenciamento costeiro: 9.760/46, 72.107/73, 7.661/88, vigentes.

Combasenos acordosinternacionais realizados pelo Brasil foicriadaaLein ${ }^{\circ} 12187 / 2009$ que estabeleceprincípios, objetivos, diretrizes einstrumentosda Política NacionaldeMudanças do Clima (PNMC). Nestecontexto, foiconstruído o Plano Nacional de Mudanças Climáticas, instrumento norteador para as três esferas de poder público, com quatro eixos de atuação: a) Oportunidades de Mitigação; b) Vulnerabilidades e Adaptação; c) Pesquisa e Desenvolvimento, d) Educação, Capacitação e Comunicação.

Assim, sugere-se a organização dos municípios para a elaboração de seus Planos Municipais de Mudanças Climáticas, para que sejam considerados os 4 eixos respeitando os limites orçamentários de cada um. Porém, ações conjuntas podem ser desenvolvidas. Os comitês de bacias dos municípios devem desenvolver ações de restituição da mata nas margens dos rios, tendo em vista que a área abriga a história do país, além de assegurar a qualidade dos ecossistemas associados e suas populações.

Ter o turismo como aliado, de forma a ordenar suas atividades culturais e naturais a fim de minimizar impactos, reduzindo a utilização de recursos fósseis, redução de resíduos sólidos e líquidos, educação ambiental, tendo em vista que na alta estação o número de visitantes é três vezes maior do que a população residente. A responsabilidade social dos empresários do turismo deve buscar reduzir as vulnerabilidades locais, oferecendo oportunidades de ocupação para o trabalhador superior a quatro meses. 
As áreas de Grau 4 (alta vulnerabilidade) em que se localizou processos erosivos, atuam na linha de costa sobretudo nas falésias e paleofalésias, que expostas ao escoamento superficial e as oscilações do nível do lençol freático têm desencadeado formação de ravinas e voçorocas, além de modificar a paisagem.

Aliados a esse processo, estudos da CI do Brasil (2013) destaca que com o aumento do nível do mar de 50 $\mathrm{cm}$, a força das ondas, ao atingir a Costa, terá um impacto maior em Porto Seguro e Santo André, distrito de Santa Cruz Cabrália. Apesar da proteção dos recifes de corais, com a elevação a esse nível do mar, estes sofrerão com a ressuspensão de sedimentos no entorno dos bancos recifais, o que pode prejudicar o crescimento dos corais. Atingirá de 10 a $60 \mathrm{~m}$ da linha da costa, impactando os hotéis e empreendimentos turísticos localizados por toda a faixa da orla norte de Porto Seguro (Reimão 2008).

Para esta situação, impõe-se a definição de uma linha de recuo, que crie uma faixa de terreno que funcione, como considera Lizárraga-Arcineiga et al. (2001), como uma barreira, permitindo assim a praia retroceder sem representar uma ameaça a infraestrutura e permitindo, ao mesmo tempo, uma área de praia para recreação.

O município de Prado apresenta os mais baixos índices de população ocupada, esgotamento sanitário e maior mortalidade infantil, pontos que devem ser analisados tendo em vista os aldeamentos indígenas e a maior área de vulnerabilidade com grau 2.

Destaca-se atenção especial para a área por conta da quantidade de rios e seu volume, que afetará o ambiente fluviomarinho num constante processo de intensa acumulação, e erosão, mas se alteradas pela força antrópica não conterá os possíveis eventos previstos às mudanças climáticas.

\section{ConClusão}

O turismo apresenta-se como uma importante atividade para os municípios, gerando emprego e renda temporários além de pagamentos de tributos aos cofres públicos locais. Porto Seguro é a principal porta de entrada de turistas para os outros municípios do extremo sul, podendo ser um modelo de ordenamento e gestão da atividade para outros municípios do MADE.

O cumprimento de leis, monitoramento de áreas e fiscalização devem estar aliadas com o poder público, privado e sociedade de forma a minimizar as vulnerabilidades em áreas, principalmente as APP's e ao longo da faixa de praia. A necessidade de desocupar e monitorar áreas ambientalmente sensíveis, poderá trazer benefícios ecossistêmicos reduzindo os efeitos da mudanças climáticas para os próximos 50 e 100 anos.

Essa utilização intensa da faixa de areia acarreta também a erosão do terreno, onde a vegetação rasteira é quase inexistente por conta do grande pisoteio, além de grande quantidade de lixo e esgoto a céu aberto, contaminando os rios e lagos existentes.

Para a área do MADE a proteção ambiental está diretamente relacionada com a proteção do patrimônio, tendo em vista que considera a primeira paisagem descrita pelos colonizadores do país. Como oportunidades, considerase apresentar o Patrimônio Histórico dos municípios com base na Interpretação do Patrimônio e valorização do acervo arquitetônico presente nas cidades históricas, assim como divulgar roteiros de visitação aos parques nacionais e unidades de conservação da área para que o visitante não se concentre apenas nas praias. Os municípios não possuem planos de enfrentamento as mudanças climáticas e com dificuldade para a gestão do esgoto, resíduos sólidos e uso e ocupação do solo.

Alerta-se, para a necessidade de qualificação dos gestores públicos municipais para possíveis impactos causados pelas mudanças climáticas, de forma a proteger os recursos naturais e seus potenciais energéticos tendo em vista que $(66,92 \%)$ da área total estão sob Grau 2 de vulnerabilidade e $(24,6 \%)$ sob grau 3. 


\section{Agradecimentos}

Os autores agradecem a Coordenação de Aperfeiçoamento de Pessoal de Nível Superior - Brasil (CAPES). Código de financiamento 001, ao Conselho Nacional de Desenvolvimento Científico e Tecnológico (CNPq) pelas bolsas de pós-graduação dos dois primeiros autores e ai CNPq pela bolsa de produtividade do último autor.

\section{REFERÊNCIAS}

Amorin RR, Oliveira RC. 2007. Degradação ambiental e novas territorialidades no extremo sul da Bahia. Caminhos de Geografia, Revista online. Uberlândia 8 (22): 18-37.

Amorin RR, Oliveira RC. 2013. Zoneamento ambiental, subsídio ao planejamento no uso e ocupação das terras da Costa do Descobrimento. Mercator, Fortaleza 12 (29): 211-231.

Bahia. 2011. Secretaria de Turismo. Superintendência de Investimentos em Polos turísticos - Suinvest. Estratégia Turística da Bahia: O Terceiro Salto 2007-2016. Secretaria de Turismo. Salvador: Setur, 100p.

Brasil. 1996. Decreto Lei no 1874, de 22 de Abril de 1996. Instituto do Patrimônio Histórico e Cultural (IPHAN). Define e delimita a área correspondente à primeira descrição geográfica do Brasil, e dá outras providências. Disponível em: http:// www.planalto.gov.br/ccivil_03/decreto/1996/D1874.htm> Acesso em: 07 abr. 2017.

Brasil. 1973. Decreto $\mathbf{n}^{\mathbf{0}}$ 72.107, de 18 de Abril de 1973. Instituto do Patrimônio Histórico e Cultural (IPHAN). Converte em Monumento Nacional o Município de Porto Seguro, no Estado da Bahia, e dá outras providências. Disponível em: $<$ http://www2.camara.leg.br/legin/fed/decret/1970-1979/decreto-72107-18-abril-1973-420741-publicacaooriginal-1-pe. html> Acesso em: 07 abr. 2017.

Brasil. 2008. Estudo de Competitividade dos 65 Destinos Indutores do Desenvolvimento Turístico Regional Relatório Brasil / Luiz Gustavo Medeiros Barbosa (Organizador). $2^{a}$ ed. Revisada. Brasília, Ministério do Turismo.

Brasil. 2009. Lei n⿳ 12.187, de 29 de Dezembro de 2009. Institui a Política Nacional sobre Mudança do Clima - PNMC e dá outras providências. Disponível em:<http://www.planalto.gov.br/ccivil_03/_ato2007-2010/2009/lei/112187.htm> Acesso em: 5 jun. 2015.

Brasil. 2016. Ministério do Turismo. Bahia tem novo mapa do turismo. Disponível em <http://www.turismo.gov. br/\%C3\%BAltimas-not\%C3\%ADcias/6466-bahia-tem-novo-mapa-tur\%C3\%ADstico.html> Acesso em 5 dez de 2016.

Brasil. 2002. Resolução $\mathbf{n}^{\mathbf{0}}$ 303, de 20 de Março de 2002. Ministério do Meio Ambiente. Dispõe sobre parâmetros, definições e limites de Áreas de Preservação Permanente. Disponível em: <http://www.mma.gov.br/port/conama/res/ res02/res30302.html>. Acesso em: 07 abr. 2017.

Carneiro RAF. 1994. A indústria de papel e celulose no Extremo Sul: estágio atual e perspectivas. Bahia: Análise e Dados, Salvador, CEI, 4, (2/3): 206-217.

Carvalho CR. 2008. Uma abordagem geográfica do Turismo em Porto Seguro. Dissertação. Dissertação apresentada ao Curso de Pós-Graduação em Geografia Física do Departamento de Filosofia, letras e Ciências Humanas da Universidade de São Paulo, São Paulo. 104 p. Disponível em: <www.teses.usp.br/teses/disponiveis/8/.../CLEBIA_RODRIGUES_DE_ CARVALHO.pdf>

Centro de Estatísticas e Informações. CEI 1992. Perfil da região econômica Extremo Sul. Salvador, 64p. 
Conservação Internacional. CI BRASIL. 2013. Levantamento da Vulnerabilidade as Mudanças Climáticas na Costa do Descobrimento e Região de Abrolhos. PEREIRA, Renata; DONATTI, Camila I.; NYBROEK, Ravic; PIDGEON, Emily; HANNAH, Lee. Brasil.

Dantas ME, Medina AI de M, Shinzato E. 2002. Geomorfologia da Costa do Descobrimento - extremo sul da Bahia: municípios de Porto Seguro e Santa Cruz Cabrália. Revista Augustus, Rio de Janeiro. 07 (14): 11p

Faria DMCP. 2007. Impacto do turismo em um destino a partir da perspectiva da economia convencional e ecológica. Revista Academia Observatório de Inovação do Turismo, 2 (3): 21p

Franco GB, Marques EAG, Gomes RL, Chagas CS, Souza CMP, Betim LS. 2011. Fragilidade ambiental da bacia hidrográfica do rio Almada - Bahia. Revista de Geografia, 28 (2): 187-205.

Instituto Brasileiro de Geografia e Estatística. IBGE. Cidades. Santa Cruz de Cabrália. Censo Demográfico 2016. Disponível em: <https://cidades.ibge.gov.br/brasil/ba/santa-cruz-cabralia/panorama> Acesso em: 8 dez. 2018.

Instituto Brasileiro de Geografia e Estatística. IBGE. Cidades. Porto Seguro. Censo Demográfico 2016. Disponível em: < https://cidades.ibge.gov.br/brasil/ba/porto-seguro/panorama>Acesso em: 8 dez. 2018.

Instituto Brasileiro de Geografia e Estatística. IBGE. Cidades. Prado. Censo Demográfico 2016. Disponível em:< https:// cidades.ibge.gov.br/brasil/ba/prado/panorama> Acesso em: 8 dez. 2018.

Iglesias F. 1992 Encontro de duas culturas: América e Europa. Estudos Avançados, 6 (14). São Paulo Jan./Apr. Disponível em < http://www.scielo.br/scielo.php?script=sci_arttext\&pid=S0103-40141992000100003> Acesso em: 10 dez. 2018

Instituto do Meio Ambiente e Recursos Hídricos. INEMA 2014. Governo do Estado da Bahia, banco de dados do INEMA 2014. Disponível em: <http://www.inema.ba.gov.br/servicos/mapas-tematicos/?dl_page=2> Acesso em: mar. 2017.

Kummerow C. 2000. The Status of the Tropical Rainfall Measuring Mission (TRMM) after Two Years in Orbit. Journal of Applied Meteorology, 39: 1965-1982.

Lizárraga-Arciniega R, Appendini-Albretchsen CM, Fischer DW. 2001. Planning for Beach Erosion: A Case Study, Playas de Rosarito, B. C. Mexico. Journal of Coastal Research, 17 (3): 636-644.

National Aeronautics and Space Administration. NASA. Goddard Earth Science Data Information and S e r v i c e s Center (GES DISC). Tropical Rainfall Measurement Mission, 2015. Disponível em: <https://disc2.gesdisc.eosdis. nasa.gov/data/TRMM_L3/TRMM_3B42.7/doc/TRMM_Readme_v3.pdf> Acesso:10 fev. 2017.

Paese A, Paglia A, Pinto LP, Foster MN, Fonseca M, Sposito R. 2010. Fine-scale sites of global conservation importance in the Atlantic forest of Brazil. Biodivers Conserv. DOI 10.1007/s10531-010-9906-x.

Palomeque FL. 2003. El turismo en el desarrollo local y regional: aportaciones conceptuales. Documento de Trabalho. Alicante: Escuela Oficial de Turismo de la Universidad de Alicante.

Pedreira M. da S. 2004. Complexo florestal, desenvolvimento e reconfiguração do espaço rural: o caso da Região Extremo Sul baiano. Bahia análise e dados, Salvador, 13(4): 1005-1018.

Peel MC, Finlayson BL, McMahon TA. 2007. Updated world map of the Koppen-Geiger climate classification. Hydrol. Earth Syst. Sci., 11: 1633-1644. 
Programa das Nações Unidas para o Desenvolvimento. PNUD 2013. Atlas do Desenvolvimento Humano. Radar IDHM. Disponível em <http://www.atlasbrasil.org.br/2013/pt/radar-idhm/> Acesso em 12 de dez. 2018.

Porto Seguro. 2014. Plano Municipal de Conservação e Recuperação da Mata Atlântica de Porto Seguro - Bahia $2^{\mathrm{a}}$ Edição. Porto Seguro. 126 p.

Reimão IS. 2008. Subsídios para a Gestão Ambiental das Praias da Costa do Descobrimento, Litoral Sul do Estado da Bahia, Brasil. Revista de Gestão Costeira Integrada - Journal of Integrated Coastal Zone Management, 8 (2): 47- 60. Associação Portuguesa dos Recursos Hídricos Lisboa, Portugal.

Spörl C, Ross JLS. 2004. Análise comparativa da fragilidade ambiental com aplicação de três modelos. GEOUSP - Espaço e Tempo, São Paulo, 15: 39-49.

Santos CS, Silva JLC. 2004. Os impactos do plantio de eucalipto e da produção de celulose em comunidades tradicionais no extremo sul baiano. Anais do II Encontro da ANPPAS, GT 17. Disponível em < http://www.anppas.org.br/encontro_ anual/encontro2/GT/GT17/gt17_jose_caetano.pdf>Acesso em: 10 nov. 2016.

Santos CZ, Schiavetti A. 2014. Spatial analysis of Protected Areas of the coastal/marine environment of Brazil. Journal for Nature Conservation (Print), 22: 1-10.

Santos NG, Franco GB, Marques EAG, Gomes RL, Chagas CS. 2014. Proposta de zoneamento geoambiental para bacia hidrográfica do rio Almada - Bahia. Revista de Geografia, 31 (2): 206-216.

Sette D. 2013. Diagnóstico Meio Biótico. In: Plano Municipal de Conservação e Recuperação da Mata Atlântica de Porto Seguro. Bahia $2^{a}$ Edição. Porto Seguro. 126 p.

Silva HR da. 2002. Rememoração"/comemoração: as utilizações sociais da memória. Revista Brasileira de História, 22, (44), 425-438.

Souza CMP, Franco GB, Gomes RL, Marques EAG, Chagas C. 2012. Zoneamento agroecológico da bacia hidrográfica do rio Almada (Bahia) com uso de sistema de informação geográfica. Espaço \& Geografia, 15 (1): 207-227.

Tagliani C. 2003. Técnica para avaliação da vulnerabilidade ambiental de ambientes costeiros utilizando um sistema geográfico de informações. Anais XI SBSR, Belo Horizonte, Brasil, 05 - 10 abril 2003, INPE: 1657 - 1664.

Teixeira ACO de, Almeida TM de, Ferreira ES. 2006. Proposta para uma periodização da história da mesorregião Sul-Baiana. In: Seminário de Iniciação Científica da UESC, 12. 2006, Ilhéus. Anais. Ilhéus: 366-367.

Tricart J. 1977. Ecodinâmica. Rio de Janeiro. IBGE. Diretoria técnica. SUPREN, 91 p.

United States Geological Survey. USGS. Shuttle Radar Topography Mission - Mission Summary. Disponível em: $<$ https://lta.cr.usgs.gov/srtm/mission_summary> Acesso:10 fev. 2017.

Velame FM. 2010. Kijemes: arquiteturas indígenas Pataxós da resistência ao espetáculo. Anais do VII ENECULT Encontro de Estudos Multidisciplinares em Cultura. Salvador, UFBA. p. 1-15. Disponível em: < http://www.cult.ufba.br/ wordpress/24254.pdf> Acesso:10 fev. 2017. 